\title{
PATTERNS OF CHROMOSOME BREAKAGE AFTER IRRADIATION AND AGEING
}

\author{
W. D. JACKSON and H. N. BARBER \\ University of Tasmania
}

Received i 9. ii. 57

\section{INTRODUCTION}

Since the discovery of the mutagenic effects of mustard gas in 1942, numerous groups of chemical substances have been shown to be active in breaking chromosomes (Loveless and Revell, 1949). In general the pattern of breakage is very similar to that induced by high energy radiations, although some authors (e.g. Ford, 1949; Revell, I953; McLeish, I953) claim to have discovered certain patterns of localisation of breaks after chemical treatments which are not apparent in X-irradiated material. Notwithstanding these reported differences in breakage pattern, the close similarity of chemical and X-ray induced breakage is hardly to be expected on a target theory as developed by Lea (1946). However, similarity would be expected if X-rays work through a chemical phase by the production of mutagenic substances or radicals which have a definite and perhaps prolonged half-life period before destruction in the cell (Gray, 195I).

The study of X-ray induced chemical reactions in watery media such as cytoplasm is still in its infancy (Read, I 95I). That the chemical phase is of critical importance in understanding irradiation damage to chromosornes is now shown by numerous lines of evidence. They include :

(I) the similarity in pattern of spontaneous and X-ray induced breakage and mutation ;

(2) the complex interactions of treatments combining a pretreatment with infra-red, ultraviolet or chemical mutagen with X-rays ;

(3) the dosage time and fractionation experiments which were initially interpreted as being due to rapid re-union and "healing" after hits on the chromosome target ;

(4) the importance of oxygen and temperature in controlling the efficiency with which X-rays break chromosomes ;

(5) the demonstration that prior irradiation of the medium on which bacteria, Neurospora spores, or Paramecium are subsequently plated out, increases mutation rate ;

(6) the existence of genetically different strains of differing X-ray sensitivity, in bacteria, viruses and Drosophila;

(7) the fact that strains which have been selected for resistance to $\mathrm{X}$-rays often show resistance to chemical mutagens and vice versa. 
If the radicals and mutagenic substances produced by ionisation after X-irradiation have an extremely short life, the target theory will hold as a limiting case. Evidence is accumulating that these substances may have a long life, and we must expect the target theory not to hold generally.

It is surprising that although claims are made that $\mathrm{X}$-irradiation and chemical breakage show the same (or different) patterns little attempt has been made since the early days of experimentation with Droscphila, to determine the exact and detailed quantitative distribution of breaks after various treatments. In this paper we shall discuss the following problems :

(a) the distribution of breaks along a chromosome ;

(b) the distribution of breaks between chromosomes of one nucleus ;

(c) the distribution of breaks between cells.

The target theory in its crudest form should predict a random distribution both between and within chromosomes. Chemical breakage, being presumably a less energetic process, might disclose weak chromosomes or weak regions within a chromosome.

Most of the previous analyses of break distribution have started with the assumption, that breaks both within and between arms are distributed at random, e.g. Newcombe (1942), Catcheside, Lea and Thoday (1946), Any non-randomness is then explained by a nonrandom re-union caused by polarisation and the movements of the broken chromosomes, or by the complication introduced into the measurement of chromosome lengths in Drosophila by heterochromatin. Many of these data might easily be explicable by assuming a nonrandom distribution of breaks between chromosomes and chromosome arms.

On the other hand, Sax and Mather (1939) and Swanson (1942) claim to have found a non-random distribution of breaks along Tradescantia chromosomes; and Koller and Ahmed (I942) have demonstrated that both induced and spontaneous breakages in the third chromosome of Drosophila are non-randomly distributed. Camara (194I) has given a thorough analysis of the X-ray breakage pattern in Triticum monococcum and shows that chromosomes are more easily broken by X-rays at the ends and near the centromere.

The distribution of breaks between cells after X-irradiation is expected to be Poissonian on the basis of a direct action theory, but need not be so after a chemical treatment which might involve thresholds and unequal dosages in addition to cumulative action.

Lea (1946) gives three sets of data which show a Poissonian distribution of breaks between cells. The mean number of breaks per cell is not given by Lea but according to his table $5^{6}$, the mean varies between $0 \cdot 25-0 \cdot 55$. Lea has not attempted to analyse Newcombe's (1942) more extensive data from this simple standpoint. As will be shown later, his data give an approximately Poissonian 
distribution with a mean of one break per cell; but as the mean break frequency is increased by increasing $\mathrm{X}$-ray dosage, the distribution departs significantly from a Poisscnian distribution, overdispersion becoming gradually more pronounced. These deviations are in the same direction as those occurring in X-rayed Drosophila sperm as analysed by Lea (loc. cit., p. 2 I9). Darlington and La Cour's (I945) data on X-rayed Trillium roots show the same tendency to overdispersion. For chemical breakage few data are available. Darlington and Koller's (I947) distributions after mustard gas treatment show overdispersion. For spontaneous breakage in Trillium (Sparrow, I949) and Tulipa (Darlington and Upcott, I94I) overdispersion is very pronounced.

Allium seed is suitable material for use in experiments on ageing and so can form a useful basis for the study of spontaneous breakage. Cytologically, it offers certain general difficulties to a complete analysis of breakage because of the number, lengths and similarity of the chromosome arms. It has the advantage of large chromosomes not possessing any visible heterochromatin regions which may complicate breakage patterns. Ford (1949), Revell (1953), McLeish (1953) and others have shown localisation of breaks in the heterochromatin after chemical treatments.

Because most divisions are in side view in root-tip preparations, scoring is more difficult than in pollen grain mitosis where ease of preparation and the haploid set are additional advantages. Notwithstanding these limitations, the root tip material from treated seeds has some outstanding advantages over the more commonly used pollen grain division.

Recent work including in particular that of Sparrow (I95I), Lane (195.3) and Haque (1953), has shown that the physiological conditions of the cell interact in many ways with the treatment producing breakage. The observable effects show that the cell has phases of quite varied "sensitivity" dependent on the type of treatment and the condition of the nucleus at the time of treatment. The treatment affects cell physiology, which in turn affects the observed result. Both sister re-union and non-sister re-union values are changed and these in turn affect the scored result. Thus, many experiments fail to give concise and consistent results because of unidentified biological interactions. In view of our inadequate knowledge of these interactions, any experimental methods which avoid or restrict these effects is preferable. If the purpose of the analysis is the study of primary breakage, then treatment of the fully dormant seed allows a directness which is not possible using other material. Dormant embryos afford stable and comparatively uniform conditions during treatment. An almost indefinite controlled delay can be made between treatments and fixation, thereby lessening physiological interactions. Lastly, the cells can be given a vider range of treatment with less physiological damage. The low non-sister re-union values and the 
virtual absence of chromatid breakage, quite apart from other advantages, make the material ideal in the study of primary breakage.

\section{MATERIALS AND METHODS}

Dormant seed of Allium cepa var. Brown Spanish was used throughout the experiment. Three stocks were used. The first was from the 1950-5 I season for the irradiation and control experiments. This seed was not more than six months old at the time of experiments. The others were two and four years old respectively. The two-year stock had such a low frequency of breakage that a detailed analysis was not carried out. Six months before observations started each of the aged stocks was divided into two lots, one of which was stored at room temperature and the other at $3^{\circ} \mathrm{C}$. This difference in storage had a marked effect on the four-year-old seed but no appreciable effect on the two-year-old. The period of storage at low temperature so markedly increased chromosome breakage in the four-year-old material that scoring was almost impossible. All subsequent data on aged seed thus refer to the four-year-old seed stored at room temperature since collection.

$\mathrm{X}$-rays were generated by a Coolidge type tube operating at $22.4 \mathrm{kV}$ (Peak) at $55 \mathrm{~mA}$, giving an intensity of $50 \mathrm{or}^{-1}$ at $10 \mathrm{~cm}$. from the target. The dose was measured by a thimble type Victoreen meter at the same distance from the target, the dose being regulated by varying the duration of irradiation. Doses of 200, $400,800,1200,1600$ and 2400 r were given, those above 400 r being administered in fractions of eight seconds, with ten seconds between fractions. The temperature at the time of irradiation was $18^{\circ} \mathrm{C}$.

The highest dose (240or) was the only dose analysed completely as it gave a mean breakage level per cell approaching that in aged seed.

Treated seeds and controls were germinated on moist filter paper at $23^{\circ} \mathrm{C}$. Radicals in the length range $3.5 \mathrm{~mm}$. on the fifth day of germination were selected, fixcd in acetic alcohol and stained in Feulgen. Within any one treatment all tips were handled in the same tube to avoid any differences in staining technique.

Sampling. Fifty root tips of each of the treatments, fresh seed, irradiated fresh seed, and aged seed were prepared as squashes. Sampling was conducted at random from the fifty slides within each treatment.

No breakage was observed in any of the fresh material. The aged material showed a marked heterogeneity in the degree of breakage between tips, as compared with the irradiated material. In both these treatments slides withdrawn were completely scored for divisions and breakage. Sampling was continued until the total number of acentric fragments in each treatment approximated 250. It was coincidental that seven slides were used in each case. Preliminary examination had shown the average level of breakage to be approximately the same. Quite apart from the enormous increase in labour involved, it was thought unwise to select for uniformity within the aged material, because the artificial removal of the heterogeneity would possibly limit the usefulness of the comparison between the two treatments. This heterogeneity is expected to make the analysis of the number of acentrics per cell (N) difficult, since the data from various roots must be treated separately. The heterogeneity is not expected to have any effect on the distribution of acentric length (X) within classes of $(\mathrm{N})$. The essential feature of the sampling method was to maintain comparable totals for both number of cells showing breakage and number of acentrics in both treatments.

Scoring. Roots were selected so that fixation coincided with the maximum initial division rate in the meristem, thus ensuring that none of the cells had passed through two divisions since treatment. Squashes were examined for :

(1) number of divisions in anaphase or early telophase :

(2) number of divisions in anaphase or early telophase showing chromosome breakage ; 
(3) number of acentrics (N);

(4) length of acentrics (X);

(5) SR in acentrics:

(6) SR and NSR in centrics.*

As mentioned in the introduction, there is very little chromatid breakage. Re-union, especially NSR, is very low (see table i showing the classified aberration
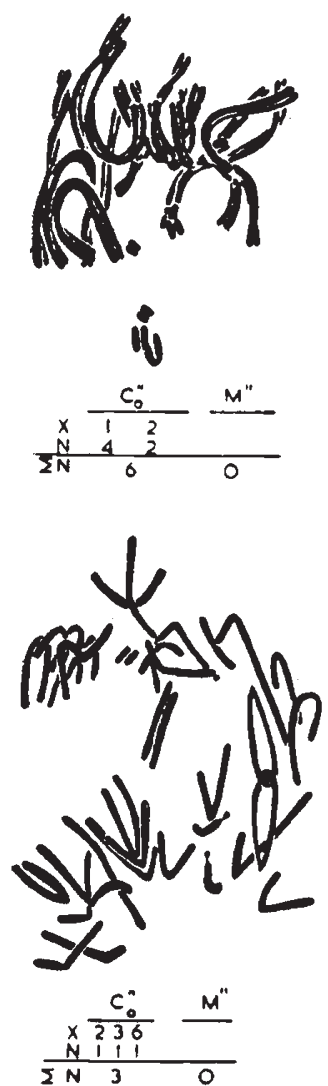

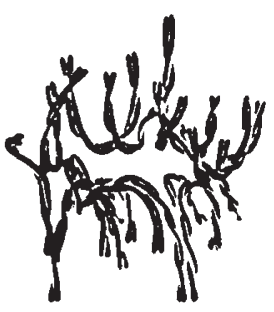

-
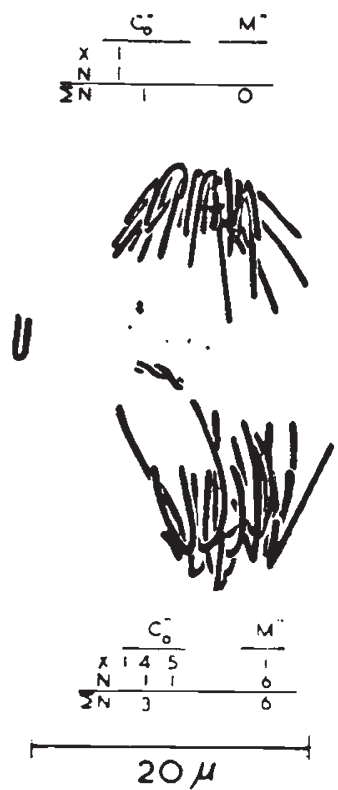
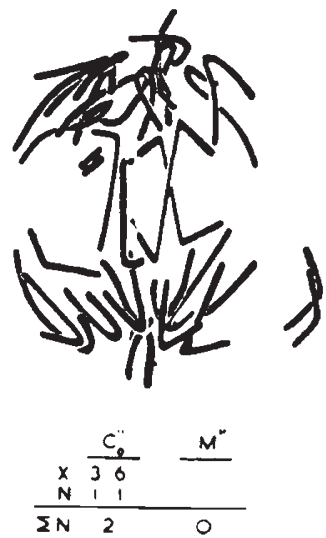

r
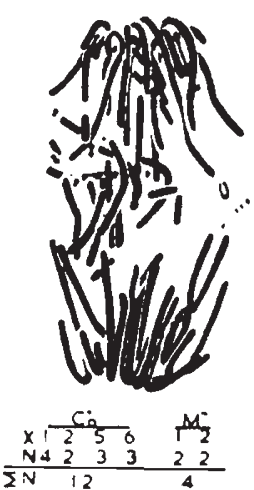

FIG. 1. - Mitotic divisions in root tip cells of germinated aged seed of Allium cepa scored for number, $\mathrm{N}$, and length, $\mathrm{X}$, of acentric fragments $\mathrm{C}_{0}{ }^{\prime \prime}$ and minutes $\mathrm{m}^{\prime \prime}$.

types). In the centrics $\mathrm{SR}$ is rarely separable from NSR, because of the uniformity in the chromosome morphology. Interchanges involving the trabant chromosome as illustrated in fig. 1, represent the only cases which may be scored with accuracy. The only practical measure of re-union for centrics is the frequency of polycentrics and since this includes both SR and NSR, it is of little use in analysis.

* We shall use Darlington and Upcoti's (1941) abbreviations and terminology. They are :

\footnotetext{
$\mathrm{C}_{0}$-acentric: $\mathrm{C}_{i_{1}}$ ctc - monocentric, dicentric, etc. $\mathrm{C}^{\prime}$-chromatid fragment : $\mathrm{C}^{\prime \prime}$-chromosome iragment.

I SR. 2 SR-single or clouble sister re-union respectively.

I NSR, 2 NSR-single or double non-sister re-union respectively.

$r$-ring: m"-paired minute.
} 
Both number and length of acentrics can be scored with a high degree of accuracy and afford the simplest and most direct measure of the initial breakage.

Apart from the occasional failure to detect very small fragments (minutes and subminutes), there are two possible cases where errors in determining $\mathrm{N}$ may arise. These are in the cells on the extremes of breakage effects. There is a greater chance of non-detection where breaks are few, since divisions without obvious fragments tend to be passed over without the rigorous examination given to cells showing breakage. Also there is a known number of cells where the number of breaks

TABLE 1

Types of aberrations

\begin{tabular}{|c|c|c|c|c|c|c|c|c|c|c|c|c|c|c|}
\hline & \multirow[b]{2}{*}{ Tip } & \multicolumn{3}{|c|}{ Divisions scored } & \multicolumn{6}{|c|}{ Acentrics } & \multicolumn{4}{|c|}{ Centrics } \\
\hline & & Total & Broken & $\mathrm{F} \% *$ & $\mathrm{C}_{0}{ }^{\prime}$ & $\mathrm{C}_{0}^{\prime \prime}$ & $\begin{array}{l}\mathrm{C}_{0}^{\prime \prime} \\
1 \mathrm{SR}\end{array}$ & $\begin{array}{c}\mathrm{C}_{0}^{\prime \prime} \\
2 \mathrm{SR}\end{array}$ & $\begin{array}{l}\mathrm{C}_{0}{ }^{\prime \prime} r \\
1 \mathrm{R}\end{array}$ & $\begin{array}{l}m^{\prime \prime} \\
1 \mathrm{R}\end{array}$ & $\begin{array}{l}\mathrm{C}_{1}^{\prime \prime} \\
1 \mathrm{SR}\end{array}$ & $\begin{array}{l}\mathrm{C}_{2}^{\prime \prime} \\
1 \mathrm{R}\end{array}$ & $\begin{array}{c}\mathrm{C}_{1}{ }^{\prime 2} 2 r \\
1 \mathrm{R}\end{array}$ & $\begin{array}{l}\mathrm{C}_{1}{ }^{\prime \prime} r \\
1 \mathrm{R} \dagger\end{array}$ \\
\hline $\begin{array}{l}\text { Aged } \\
\text { seed }\end{array}$ & $\begin{array}{l}1 \\
2 \\
3 \\
4 \\
5 \\
6 \\
7\end{array}$ & $\begin{array}{r}206 \\
177 \\
270 \\
105 \\
200 \\
76 \\
174\end{array}$ & $\begin{array}{r}4 \\
14 \\
2 \\
20 \\
7 \\
23 \\
33\end{array}$ & $\begin{array}{r}2 \\
15 \\
I \\
2 I \\
3 \\
76 \\
14\end{array}$ & $\begin{array}{c}\ldots \\
\ldots \\
\ldots \\
1 \\
\ldots \\
1 \\
\ldots\end{array}$ & $\begin{array}{r}7 \\
18 \\
5 \\
46 \\
10 \\
73 \\
64\end{array}$ & $\begin{array}{r}1 \\
4 \\
\ldots \\
3 \\
\ldots \\
7 \\
2\end{array}$ & $\begin{array}{c}\ldots \\
1 \\
\ldots \\
\ldots \\
\ldots \\
1 \\
1\end{array}$ & $\begin{array}{c}\ldots \\
\ldots \\
\ldots \\
1 \\
\ldots \\
\ldots \\
\cdots\end{array}$ & $\begin{array}{r}\cdots \\
13 \\
\cdots \\
8 \\
9 \\
5 \\
3\end{array}$ & $\begin{array}{r}\ldots \\
4 \\
\ldots \\
7 \\
2 \\
13 \\
6\end{array}$ & $\begin{array}{c}\ldots \\
\ldots \\
\cdots \\
\cdots \\
\ldots \\
\ldots \\
\cdots\end{array}$ & $\begin{array}{c}\ldots \\
\ldots \\
\ldots \\
\ldots \\
\ldots \\
1 \\
\ldots\end{array}$ & $\begin{array}{c}\ldots \\
\ldots \\
\ldots \\
\cdots \\
\cdots \\
\cdots \\
\cdots\end{array}$ \\
\hline Total & 7 & 1208 & 103 & 9 & 2 & 223 & 17 & 3 & 1 & $3^{8}$ & 32 & 1 & 1 & $\cdots$ \\
\hline $\begin{array}{l}\text { Fresh } \\
\text { seed } \\
\text { X-rayed } \\
\text { (24oor) }\end{array}$ & $\begin{array}{l}1 \\
2 \\
3 \\
4 \\
5 \\
6 \\
7\end{array}$ & $\begin{array}{l}207 \\
252 \\
322 \\
217 \\
195 \\
236 \\
105\end{array}$ & $\begin{array}{l}22 \\
16 \\
49 \\
27 \\
21 \\
16 \\
22\end{array}$ & $\begin{array}{r}I I \\
6 \\
I 5 \\
I 2 \\
I I \\
7 \\
2 I\end{array}$ & $\begin{array}{c}1 \\
\ldots \\
2 \\
\cdots \\
\ldots \\
\cdots \\
\cdots\end{array}$ & $\begin{array}{l}31 \\
22 \\
46 \\
30 \\
27 \\
20 \\
28\end{array}$ & $\begin{array}{l}3 \\
4 \\
5 \\
4 \\
1 \\
3 \\
3\end{array}$ & $\begin{array}{c}1 \\
1 \\
2 \\
\ldots \\
\ldots \\
\ldots \\
1\end{array}$ & $\begin{array}{c}1 \\
\ldots \\
\ldots \\
\ldots \\
\ldots \\
\ldots \\
\ldots\end{array}$ & $\begin{array}{r}1 \\
\ldots \\
10 \\
4 \\
5 \\
6 \\
3\end{array}$ & $\begin{array}{l}3 \\
7 \\
8 \\
1 \\
1 \\
5 \\
3\end{array}$ & $\begin{array}{c}1 \\
\ldots \\
\cdots \\
\ldots \\
\cdots \\
\cdots \\
\ldots\end{array}$ & $\begin{array}{c}\ldots \\
1 \\
\ldots \\
\ldots \\
\ldots \\
\ldots \\
\ldots\end{array}$ & $\begin{array}{c}\ldots \\
\ldots \\
\ldots \\
\ldots \\
\ldots \\
\ldots \\
1\end{array}$ \\
\hline Total & 7 & 1534 & 173 & $I I$ & 3 & 204 & $\underbrace{23}_{232}$ & 5 & 1 & 29 & 28 & 1 & 1 & 1 \\
\hline
\end{tabular}

* This column gives the frequency per cent. of broken cells including those unscorable, as a measure of net breakage for estimation of heterogeneity.

$\div \mathrm{SR}=$ sister re-union. $\mathrm{R}=$ non-sister re-union. Where type of union is ambiguous the more probable condition is assumed.

exceeds 15 to 20 , the disorganised mass of fragments being beyond scoring with accuracy. In only a few tips of the aged material do the numbers of such cells exceed 5 per cent. of the scorable divisions.

Natural variation in chromatid contraction renders extreme accuracy unnecessary in the measurement of acentric length. Where fragments were oblique to the optical axis, true lengths were calculated from the apparent lengths measured on the ocular micrometer and the vertical height-given by readings of the fine adjustment spindle micrometer under restricted depth of field conditions. Fragment. lengths were grouped to the nearest $\mu$, which is well within the range of contraction. It is not possible to relate fragments to specific chromosomes, or parts of chromosomes, as Camara has done in Triticum, or as McLeish and Revell have done in Vicia. Nor is it possible to obtain specific cell constants for the degree of contraction, 
owing to the difficulties of identifying particular arms consistently. These limitations can, however, be largely overcome by a simple statistical treatment of the data, which will be discussed with the results.

Minutes $\left(\mathrm{m}^{\prime \prime}\right)$ are separated from fragments $\left(\mathrm{C}_{0}{ }^{\prime \prime}\right)$ on diameter. All fragments have been scored as $\mathrm{C}_{0}{ }^{\prime \prime}$ if the diameter is the same as the chromatid diameter. Most of the minutes are identical paired bodies and show no sister re-union. They are assumed to be paired rings. The diameter of the thread is always less than half the chromatid diameter.

\section{TYPES OF BREAKAGE}

The classified results of scoring are shown in table I. The similarity between the aged seed and the irradiated fresh seed is at once apparent. The outstanding difference is the heterogeneity in the breakage level between roots in the aged seed. Germination in the aged seed is, of course, reduced compared with that of fresh seed. Post-germination death is also evident in the aged seed. The irradiation of fresh seed by doses of the order of $3 \mathrm{Kr}$. reduces its viability by only a small amount.

The pattern of aberration types is strikingly similar. Chromaticl breakage is doubtfully present ; SR is low and NSR almost absent ; micro-acentrics have a fairly high frequency of occurrence. Fig. I shows some typical divisions from aged seed material and illustrates the scoring conventions used.

This general pattern is remarkably different from that obtained in the irradiation of actively dividing root tips, where chromatid breaks and re-unions of various types are frequent. More surprisingly, it shows marked differences from the results obtained by irradiating pollen grains in the immediate post-meiotic stage. Although the nuclei are in an apparent resting condition in pollen, NSR is frequent and the proportion of simple deletions is lower than in the dormant seed material.

Tables 2-8 give the data in a form suitable for consideration of the four problems of the distribution of breakage within chromosomes, between chromosomes of the same nucleus, between nuclei and between root tips.

\section{DISTRIBUTION OF BREAKS WITHIN AND BETWEEN CHROMOSOMES}

Table 2 and fig. 2 give the distribution of length in acentric fragments. The distributions in aged and X-rayed cells are very similar in form, most fragments (c. 6o per cent.) being less than 25 per cent. of the length of the average chromosome arm. There is a subsidiary maximum frequency at about the mean arm length $(6 \cdot 5 \mu)$.

The detailed analysis of these distributions requires the calculation of the distribution expected assuming a random position of breakage along the length of all chromosomes. For any particular chromosome 
arm $\nu$, and for only one break, the expected distribution of acentric length $(\mathrm{X})$ is obviously a simple rectangular distribution,

$$
d p=\frac{\mathrm{I}}{l_{v}} d x
$$

where $l_{\nu}$ is length of chromosome arm.

TABLE 2

Frequency distribution of $X$, length of acentrics $C_{0}{ }^{\prime \prime}$

Total distributions given for $(a)(N>1)$ one or more fragments per cell.

(b) $(\mathrm{N}=\mathrm{I})$ one fragment per cell.

\begin{tabular}{|c|c|c|c|c|c|c|c|c|c|c|c|c|c|c|c|c|c|}
\hline & & & & & ength & of ac & entric & $\mathrm{C}_{0}^{\prime \prime}$ & grou & ped $t$ & o the & nea & rest & integ & al $\mu$ & & \\
\hline & & & 1 & 2 & 3 & 4 & 5 & 6 & 7 & 8 & 9 & IO & I I & 12 & $f_{\mathrm{x}}$ & $x_{x}$ & $V_{x}$ \\
\hline Aged seed & & I & 4 & I & I & $\cdots$ & I & $\cdots$ & $\cdots$ & $\cdots$ & I & $\ldots$ & $\cdots$ & $\cdots$ & 8 & $2 \cdot 9$ & $8 \cdot I$ \\
\hline & & 2 & 9 & 4 & 2 & 3 & 3 & 2 & $\ldots$ & $\ldots$ & $\ldots$ & $\cdots$ & $\cdots$ & $\ldots$ & 23 & $2 \cdot 7$ & $3 \cdot 2$ \\
\hline & & 3 & 2 & $\cdots$ & 2 & $\cdots$ & $\cdots$ & $\cdots$ & I & $\cdots$ & $\cdots$ & $\ldots$ & $\cdots$ & $\cdots$ & 5 & $2 \cdot 8$ & $6 \cdot 5$ \\
\hline & & 4 & 26 & 6 & 7 & $\cdots$ & 5 & 5 & $\cdots$ & $\cdots$ & I & $\cdots$ & $\cdots$ & $\cdots$ & .50 & $2 \cdot 5$ & $4 \cdot 3$ \\
\hline & & 5 & 1 & 3 & 3 & 2 & I & $\cdots$ & $\cdots$ & $\ldots$ & $\cdots$ & $\ldots$ & $\ldots$ & $\ldots$ & 10 & $2 \cdot 9$ & $2 \cdot 1$ \\
\hline & & 6 & 24 & 18 & 20 & 2 & 4 & 7 & 2 & I & I & $\ldots$ & $\cdots$ & 2 & $8 I$ & $3 \cdot 0$ & $5 \cdot 6$ \\
\hline & & 7 & 39 & & 4 & 2 & I & 7 & 2 & I & $\cdots$ & $\cdots$ & $\cdots$ & $\cdots$ & 66 & $2 \cdot 3$ & 5.0 \\
\hline Total $(a)$ & - & $N>I$ & I05 & 42 & 39 & 9 & I 5 & 21 & 5 & 2 & 3 & $\cdots$ & $\ldots$ & 2 & 2.43 & 2.7 & $4 \cdot 6$ \\
\hline Total $(b)$ & . & $N=I$ & 25 & 8 & 8 & I & 2 & 7 & 3 & I & $\cdots$ & $\cdots$ & $\cdots$ & $\cdots$ & $5 . \overline{5}$ & $2 \cdot 7$ & 4.7 \\
\hline Expected & • & $\mathbf{N}=\mathrm{I}$ & $8 \cdot 3$ & $8 \cdot 3$ & $8 \cdot 3$ & $8 \cdot 0$ & $7 \cdot 5$ & $6 \cdot 2$ & $3 \cdot 6$ & $3 \cdot 4$ & $\mathrm{I} \cdot \mathrm{O}$ & 0.5 & $\cdots$ & $\cdots$ & 55 & $3 \cdot 9$ & $6 \cdot 3$ \\
\hline Fresh seed & & I & 10 & 8 & 2 & 4 & 2 & 3 & 4 & 2 & $\cdots$ & $\cdots$ & $\ldots$ & $\cdots$ & 35 & 34 & 5.9 \\
\hline irradiated & & 2 & 9 & I I & 2 & 3 & $\cdots$ & $\cdots$ & 2 & $\cdots$ & $\cdots$ & $\cdots$ & $\cdots$ & $\cdots$ & 27 & $2 \cdot 3$ & $2 \cdot 8$ \\
\hline (240or) & & 3 & 25 & Io & 5 & 3 & 4 & 2 & 3 & I & $\cdots$ & $\cdots$ & $\cdots$ & $\cdots$ & 53 & $2 \cdot 6$ & $5 \cdot 2$ \\
\hline & & 4 & I 5 & 5 & 4 & 2 & $\cdots$ & 2 & 3 & 2 & $\cdots$ & $\cdots$ & I & $\cdots$ & 34 & $3 \cdot 1$ & $7 \cdot 4$ \\
\hline & & 5 & 10 & 8 & 2 & I & 2 & 4 & $\cdots$ & $\cdots$ & $\cdots$ & I & $\cdots$ & $\cdots$ & 28 & 2.9 & $5 \cdot 3$ \\
\hline & & 6 & 7 & 4 & 3 & I & 1 & 3 & 2 & 2 & $\ldots$ & $\ldots$ & $\ldots$ & $\cdots$ & 23 & 3.5 & 6.6 \\
\hline & & 7 & 10 & 7 & 5 & 2 & $\cdots$ & 2 & 3 & I & I & $\ldots$ & $\cdots$ & I & $3^{2}$ & 3.4 & $7 \cdot 9$ \\
\hline Total $(a)$ & - & $N>I$ & 86 & 53 & 23 & 16 & 9 & 16 & I 7 & 8 & I & $x$ & I & I & 232 & 2.9 & $5 \cdot 5$ \\
\hline Total $(b)$ & - & $N=I$ & 60 & 25 & I I & 8 & 5 & 5 & 7 & 3 & I & I & 1 & I & 128 & $2 \cdot 7$ & $5 \cdot 8$ \\
\hline Expected & - & $N=I$ & $19 \cdot 2$ & $19 \cdot 2$ & $19 \cdot 2$ & $18 \cdot 6$ & $17 \cdot 4$ & 14.4 & $8 \cdot 4$ & $7 \cdot 8$ & $2 \cdot 4$ & $I \cdot 2$ & $\cdots$ & $\cdots$ & $I 28$ & $4^{\circ} 0$ & $5^{\circ} 1$ \\
\hline
\end{tabular}

Where there are $j$ arms of lengths $l_{1}, l_{2}, \ldots$, the probability of obtaining a single fragment of length $x$ units from any one of the $i$ arms is the reverse sum polygon of the lengths of the $j$ arms.

$$
d p=\stackrel{x}{\Sigma} \nu \max \left(l_{\nu} ; l_{j}\right) \int_{\mathrm{x}}^{\underset{\Sigma}{j} \nu} \quad(\mathrm{I} \leqslant \nu \leqslant j)
$$

In Allium where it is impossible to recognise the donor chromosome arm, this distribution gives the only practical method of determining the distribution expected from random breakage. Table 3 gives the lengths of the 16 chromosome arms of the haploid complement. For 

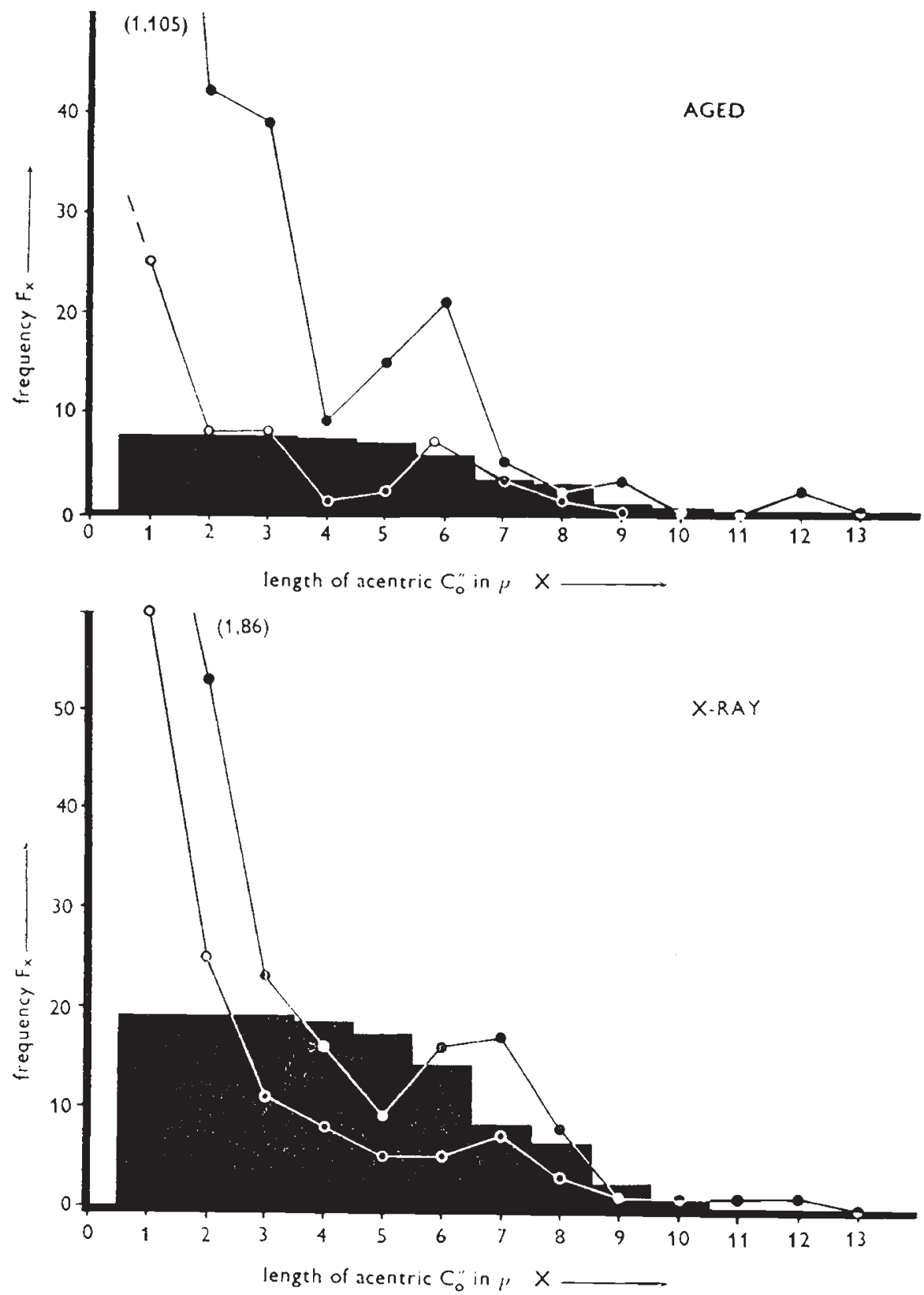

FIG. 2.- Graphs giving data from table 2, showing the frequency distribution length, $\mathrm{X}$, of acentric fragments in cells where (the number of fragments) $N \geqslant 1$ (blacked circles) and $\mathrm{N}=\mathrm{I}$ (hollow circles). The blacked histogram gives the distribution for $\mathrm{N}=\mathrm{I}$ of fragment length cxpccted if the breaks are distributed at random along the chromosomes. 
ease of measurement the relative lengths of the arms were determined in slight C-mitosis where the chromosomes are straight and the centromeres easily visible. These relative values were then transformed into actual mean lengths by applying a conversion factor determined by measuring the length of the trabant chromosome in all favourable

TABLE 3

Mean arm length $\bar{l}$ at anaphase in microns

\begin{tabular}{|c|c|c|c|c|c|c|c|c|}
\hline Chromosome & A & B & C & $\mathrm{D}$ & $\mathrm{E}$ & F & G & $\mathrm{H}$ \\
\hline Arm $a$ & $8 \cdot 0$ & $9 \cdot 6$ & $8 \cdot 0$ & $8 \cdot 3$ & $7 \cdot 4$ & $8 \cdot 4$ & $6 \cdot 2$ & $6 \cdot 2$ \\
\hline $\operatorname{Arm} b$ & $7 \cdot 6$ & $6 \cdot 0$ & $6 \cdot 4$ & $5 \cdot 2$ & $5 \cdot 6$ & $3 \cdot 5$ & $5 \cdot 1$ & $4 \cdot 5$ \\
\hline Total length & 15.6 & $15 \cdot 6$ & $14 \% 4$ & 13.5 & $x_{3} \cdot 1$ & $12 \cdot 4$ & $x x \cdot 3$ & 10.7 \\
\hline
\end{tabular}

divisions during scoring in both aged and X-rayed root tips. Forty measurements of the trabant chromosome gave a mean length of I $2 \cdot 4 \pm 0 \cdot 5 \mu$.

Table 4 gives the derivation of the probability distribution of length of acentric fragments where only one fragment is present in the cell $(\mathrm{N}=\mathrm{I})$. These distributions are shown as the blacked-in

TABLE 4

Derivation of the probability distribution of acentric fragment length $X$

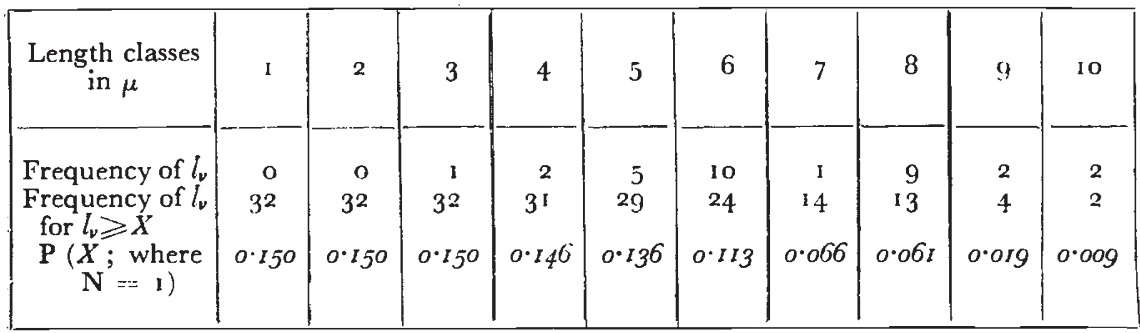

$l_{v}=$ mean length of the $v$ th arm.

$\mathrm{X}=$ Iength of acentric fragment $\mathrm{C}_{0}{ }^{\prime \prime}$.

$N=$ number of fragments $\mathrm{C}_{0}$ " per cell.

histogram of fig. 2. It is clear from these figures that fragments of length less than $2 \mu$ are in great excess whilst there is a deficiency of fragments of lengths $3-5 \mu$. Table 5 gives an analysis of these deviations by $\chi^{2}$ and leaves no doubt as to their statistical significance.

There are four acentric fragments in the two treatments which exceed the mean length of the longest arm. It is possible that these long fragments arise by NSR between shorter fragments. However, variations in degree of contraction of the trabant chromosome give an estimated standard error for long fragments of almost $0.5 \mu$. 
Thus it is likely that these extreme lengths are simply due to normal variations in degree of contraction of the chromosomes. There is, thus, no conclusive evidence of NSR in the acentrics.

Where there is more than one fragment in the cell a donor may contribute more than one fragment. The expected distribution of fragment length for such conditions is complex since for $\mathrm{N}$ fragments per cell $(\mathrm{N}>\mathrm{I})$, the probability of any arm $\nu$ donating any number $r$, $(\mathrm{I}<r \leqslant \mathrm{~N})$, of the $\mathrm{N}$ fragments is,

$$
\left[\frac{l_{v}}{\Sigma l_{v}}\right]^{r} \cdot\left[\frac{\Sigma l_{v}-l_{v}}{\Sigma l_{v}}\right]^{\mathrm{N}-r}=\frac{l_{v}^{r}\left(\Sigma l_{v}-l_{v}\right)^{\mathrm{N}-r}}{\left[\Sigma l_{v}\right]^{\mathrm{N}}}
$$

Since $l_{v}$ is small with respect to $\Sigma l_{v}$ and the mean $N$ is small with respect to the number of donors, this probability is small if breakage

TABLE 5

$\chi^{2}$ for grouped classes of acentric fragment length $X$

\begin{tabular}{|c|c|c|c|c|c|}
\hline Class & $\mathrm{I}-2 \mu$ & $3-5 \mu$ & $6-7 \mu$ & $8.10 \mu$ & Total \\
\hline $\begin{aligned} \chi^{2} \text { Aged } N & =1 \\
\text { Aged } N & =1\end{aligned}$ & $\begin{array}{l}33 \cdot 6 \\
75 \cdot 0\end{array}$ & $\begin{array}{l}10 \cdot 2 \\
21 \cdot 0\end{array}$ & $\begin{array}{l}0 \cdot 2 \\
4 \cdot 8\end{array}$ & $\begin{array}{l}3 \cdot 2 \\
8 \cdot 8\end{array}$ & $\begin{array}{r}47 \cdot 2 \\
108 \cdot 6\end{array}$ \\
\hline $\begin{array}{r}\chi^{2} \text { Irradiated } N=1 \\
\text { Irradiated } N \geqslant 1\end{array}$ & $\begin{array}{l}88 \cdot 2 \\
69 \cdot 0\end{array}$ & $\begin{array}{l}18 \cdot 5 \\
27 \cdot 6\end{array}$ & $\begin{array}{l}6 \cdot 4 \\
3 \cdot 2\end{array}$ & $\begin{array}{l}3 \cdot 7 \\
5 \cdot 2\end{array}$ & $\begin{array}{l}116 \cdot 7 \\
105 \cdot 0\end{array}$ \\
\hline
\end{tabular}

per unit length is equal in all chromosomes. However, if there are marked differences in susceptibility between arms, those arms which are more easily broken will have reasonably large values of the above probability. The net effect of such conditions would lead to a marked alteration in the form of the distribution, since if any arm donates $r$ fragments, the length distribution becomes a $\beta(\mathrm{I}, r)$ distribution, which for $r>1$, gives a rapid increase in the probability of short fragments as $r$ increases.

Table 2 and fig. 2 show that the distributions of $\mathrm{X}$ are the same for cases of $N=I$ and $N \geqslant I$. There is no suggestion that short fragments tend to occur more frequently in cells with a high $\mathrm{N}$. This is also shown by the fact that there is no significant negative correlation between $\mathrm{X}$ and $\mathrm{N}(r=+0.03, \mathrm{P}=0.7$ for aged seed and $r=+0.15$, $\mathrm{P}=0.2$ for X-rayed seed). Within the limits of these comparisons it seems safe to conclude that the chance of breakage per unit length does not vary greatly between different chromosomes of the complement. Even if a more precise analysis, e.g. by counting breaks in the easily identified chromosomes, as has been done by McLeish (1953) for Vicia, should show a range in susceptibility to breakage between chromosomes, this range must be small and substantially the same for aged and X-rayed seed. 
It has already been shown that the frcquency of NSR in both centrics and acentrics is very low in this material. This means that almost all acentrics are terminal deletions and that a particular length of fragment can be related to a fixed region in the mean arm length. Thus, we may conclude that the chance of breakage (or the chance of persistence of a break until the time of observation) after both ageing and X-ray treatment, is most frequent at the ends of all chromosomes, while mid-arm regions have the least chance of breakage, there being a smaller increase in the chance of breakage in the centromere regions. These findings are very similar to those of Camara (I94I) for the trabant chromosomes of Triticum monococcum. In Triticum the chances of breakage are almost equal near the ends and near the centromere. In Allium the chance appears to be much higher near the ends than near the centromere. However, some of this difference may be due to the three-fold $(3.5 \mu-9.6 \mu)$ range in length of chromosome arms in Allium.

Ford (1949, see also Gray, I95 I, p. 264) has shown non-random breakage in Vicia using nitrogen mustard, but claims, in contrast to the present results, that the distribution after $\mathrm{X}$-irradiation is random. His results seem hardly extensive enough to prove the latter point conclusively.

Similar non-random distributions in Vicia have been demonstrated by Deufel (195I), Revell (1953,) and McLeish (1953) using various chemical agents. Revell (1953) states that the X-ray induced breaks in the long chromosome are apparently at random. However, calculations based on data from his diagram do not support this statement. Deufel (195I) obtained a markedly non-random distribution for breaks in the same chromosome using $\mathrm{X}$-irradiation. It is difficult to say without full data, whether there is heterogeneity between the different chemical treatments, or even between these and the $\mathrm{X}$-ray data. In this respect it is interesting to notice that an analysis of breakage in the X-chromosome of Drosophila conducted by Fahmy and Bird (I953) indicated that the patterns produced by a diepoxy-butane, an imino-substituted triazine and a sulphur mustard, were not significantly different.

It has been claimed that the localisation of breakage by chemical agents is associated with regions rich in heterochromatin. On this basis Loveless (1953) has suggested different mechanisms for the action of ionising radiation and of radiomimetics. The present results do not in any way support this view. Although there may well be certain differences in detail, the similarities to be found are so numerous that it would seem the mechanisms have at least some common basis.

So far we have discussed the distribution of length of acentric fragments in terms of a non-random primary breakage. It is possible that part or the whole of the observed localisation of breaks is dependent on the chance of restitution varying along the length of the chromosomes, perhaps in consequence of the polarisation from the previous 
telophase. However, it is doubtful whether non-random restitution need seriously be considered as an alternative to non-random breakage since re-union of all scorable kinds occurs at such a low frequency. We have seen that the length of acentric fragments gives no indication of NSR. SR accounts for most of the scorable re-unions; but even these number only about IO-I5 per cent. of the total possible in the observable breaks. This is to be contrasted with data from the irradiation or chemical treatment of actively metabolising cells where $5^{\circ}$ per cent. of breaks may show NSR (e.g. Lanc, 195I ; Darlington and Koller, 1947).

The micro-acentrics have been omitted from the above analysis. They are probably paired rings of diameter less than half of the chromatids and appear to be small interstitial deletions with a length about that of one gyre of the chromosome helix. There is a clear discontinuity in thickness between the minutes and the smallest class of acentrics considered in the above analysis. To avoid including any minutes in the distribution of $\mathrm{X}$ and thus overloading the class of frequencies of the shortest acentrics, all fragments less than $0.5 \mu$ have been classified as minutes.

\section{DISTRIBUTION OF BREAKS BETWEEN NUCLEI}

Tables 6 and 7 give the distributions of numbers of breaks between cells of the same root tip and between root tips. These tables show that the mean number of breaks induced in dormant seeds shows great variation between seeds. The heterogencity is much greater in the aged than in the irradiated seed. It presumably indicates that seeds differ greatly in sensitivity to ageing and to a lesser extent to irradiation. The cause of the variation may be a range in permeability governing water or oxygen content in the air-dry seeds.

As regards the distribution of breaks between cells of the same seed, if the breaks are caused by statistically independent events, these distributions for the individual root tips should be Poissonian. In view of the marked heterogeneity between tips, it is probably better to restrict the analysis to individual distributions. In the Poisson clistribution, the mean and the variance are equal. The variance $/$ mean ratio gives an efficient test of the Poissonian nature of a distribution. This test is preferable to a direct $\chi^{2}$ test on the observed class frequencies as used, e.g. by Lea (1946), since it avoids the grouping of terminal classes and it preserves any trends in the deviations from expectation. The significance of deviations of the ratio from unity can be tested by using the ratio of the sum of squares to the mean which has a $\chi^{2}$ distribution (Sukhatme, 1938).

Values of the variance/mean ratio and the significance of their deviations from unity, expressed as normal deviates, are shown in tables 6 and 7. All aged material and all but one of the irradiated serds show significant overdispersion $\mathrm{V}_{x} / \bar{x}>\mathrm{I}$, with deviations ranging 
W. D. JACKSON AND H. N. BARBER

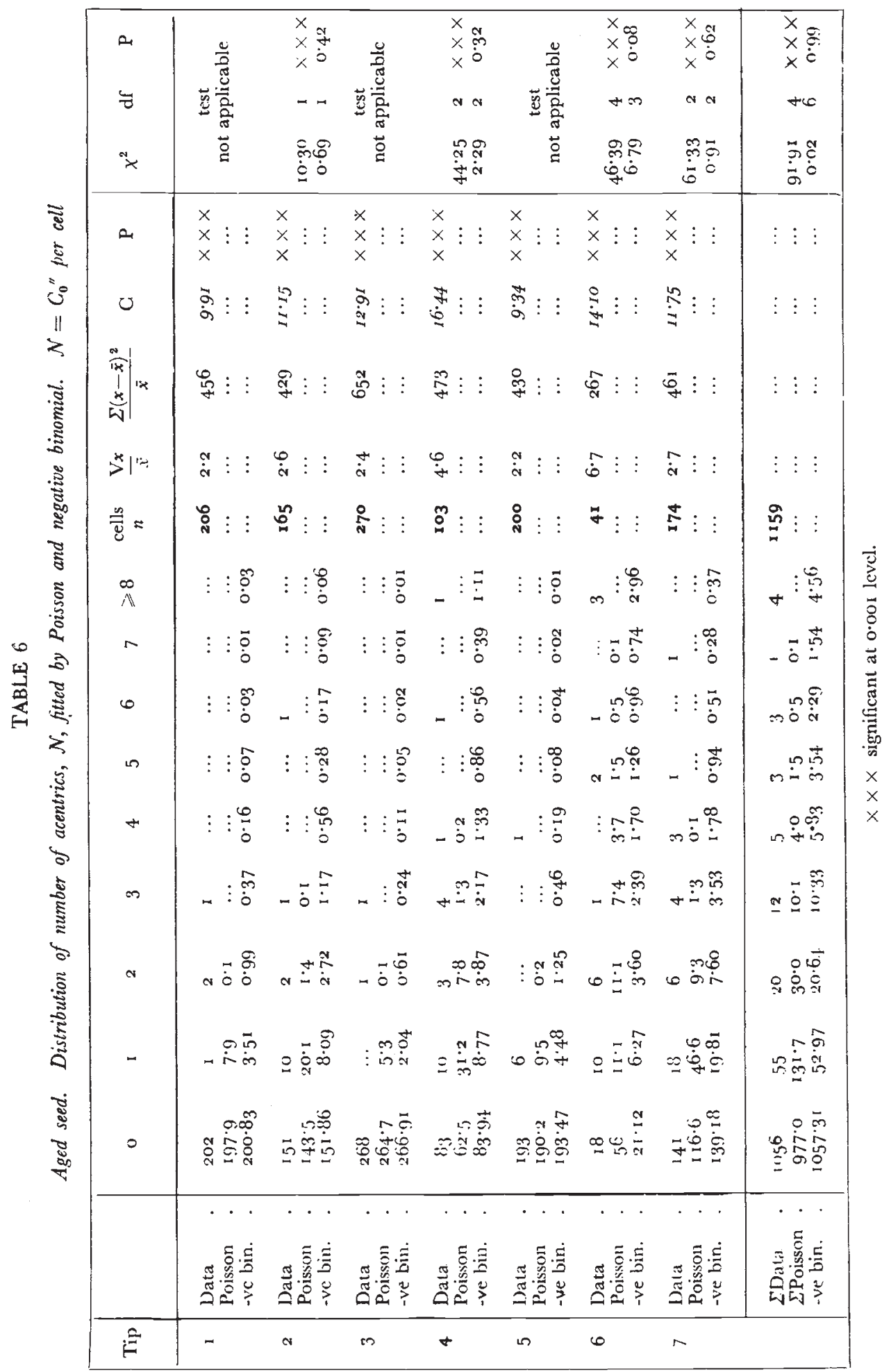




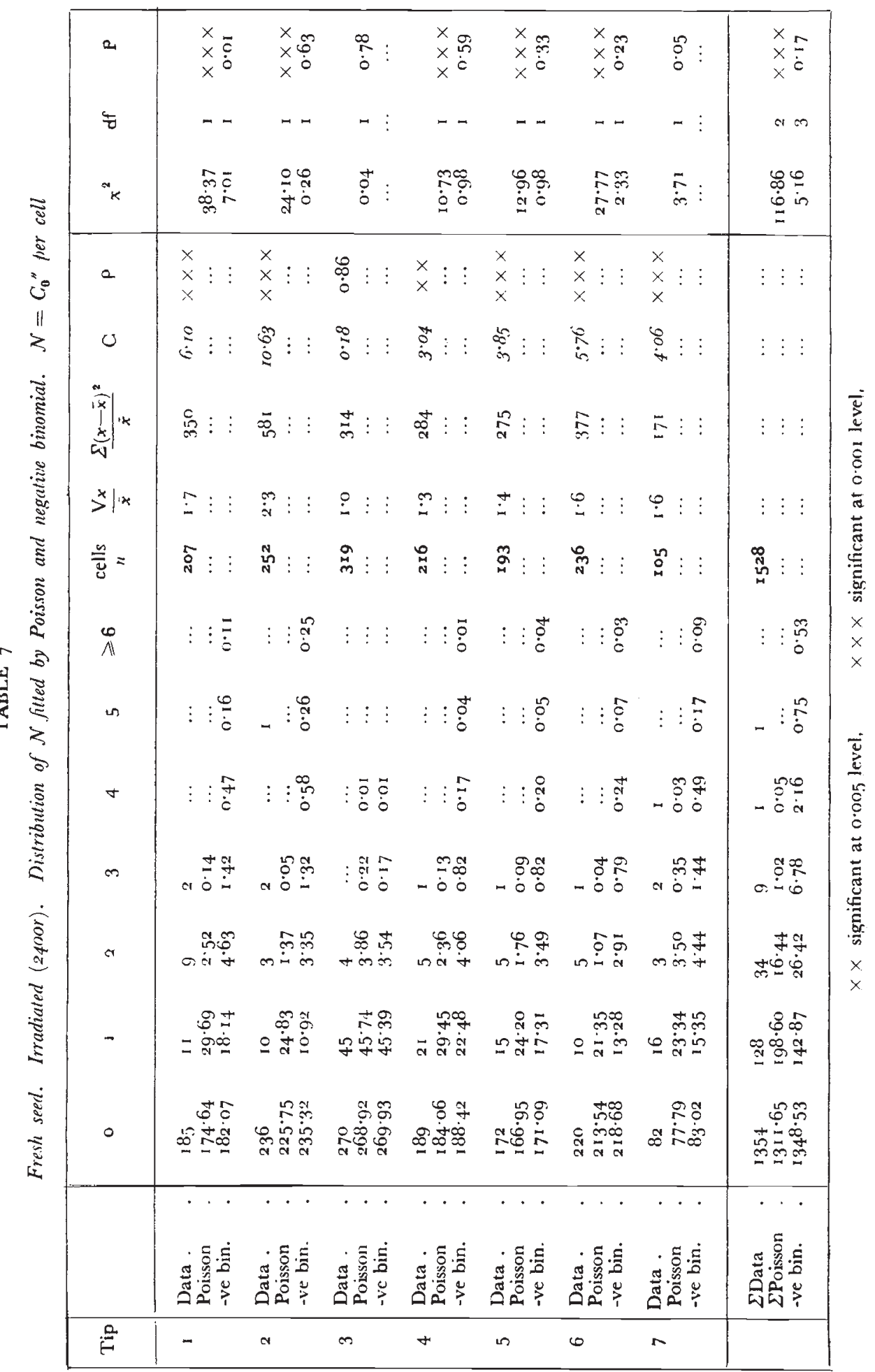


from 3 to 16 times their standard errors. Fig. 3 shows the data graphically, the variance/mean ratio being plotted against the mean. The greatest range of acceptance for the Poisson with limits at the 5 per cent. level of significance is shown. The graph illustrates clearly the heterogeneity in mean breakage level between different seeds and the departure from the Poissonian expectation. Further, in the aged seeds there is evidence that overdispersion increases with the mean number of breaks. The trend is the more significant since cells

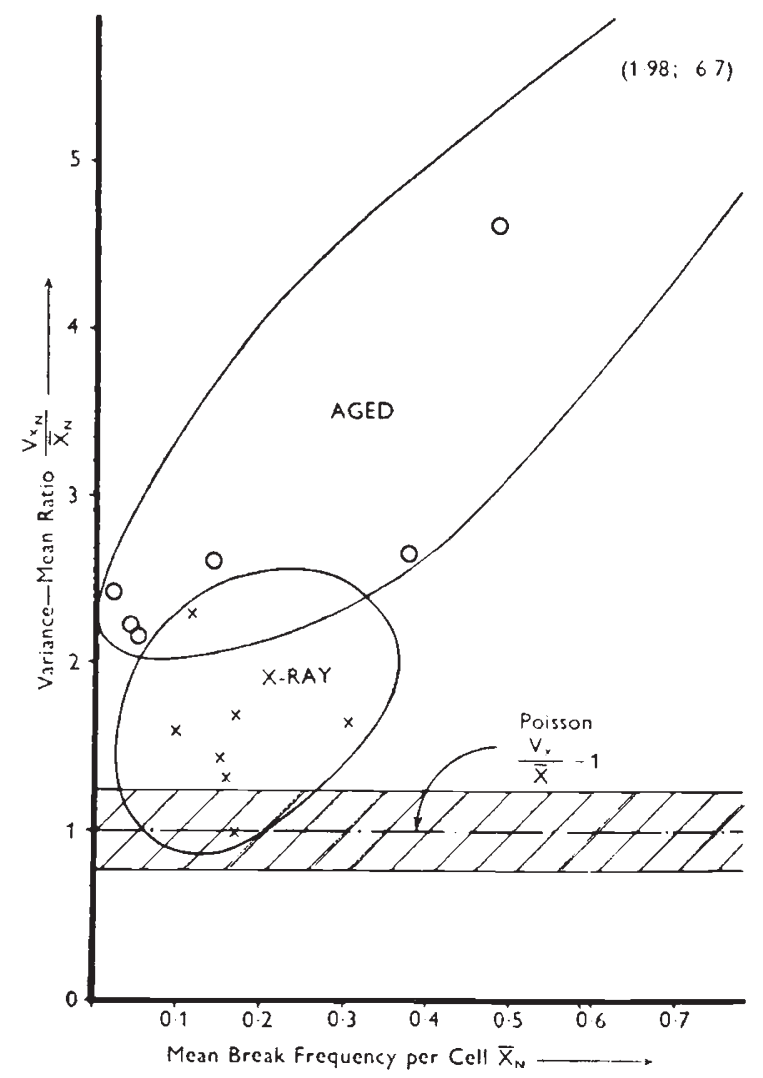

Fig. 3.-Relationship of the variance/mean ratio to the mean number of acentrics per cell showing the maximum fiducial limit ( 5 per cent. level) of acceptance of the Poissonian expectation $\left(\mathrm{V}_{x} / \tilde{x}=1\right)$.

unscorable because of high numbers of breaks are more frequent in the roots with high breakage levels. The trend towards increased overdispersion with increased numbers of breaks is not apparent in the X-rayed seed. This may be due to the lower variation in the mean breakage level. However, six of the seven roots show undoubted overdispersion.

It is surprising that this overdispersion in $\mathrm{X}$-ray data has not been demonstrated by previous investigators. Lea (p. 218, 1946) gives a partial analysis of the data available at that time. He fails to inclucle for example, data from Newcombe (1942) and Darlington and La Cour (1945). Figs. 4 and 5 show the results of an analysis of dispersion in 


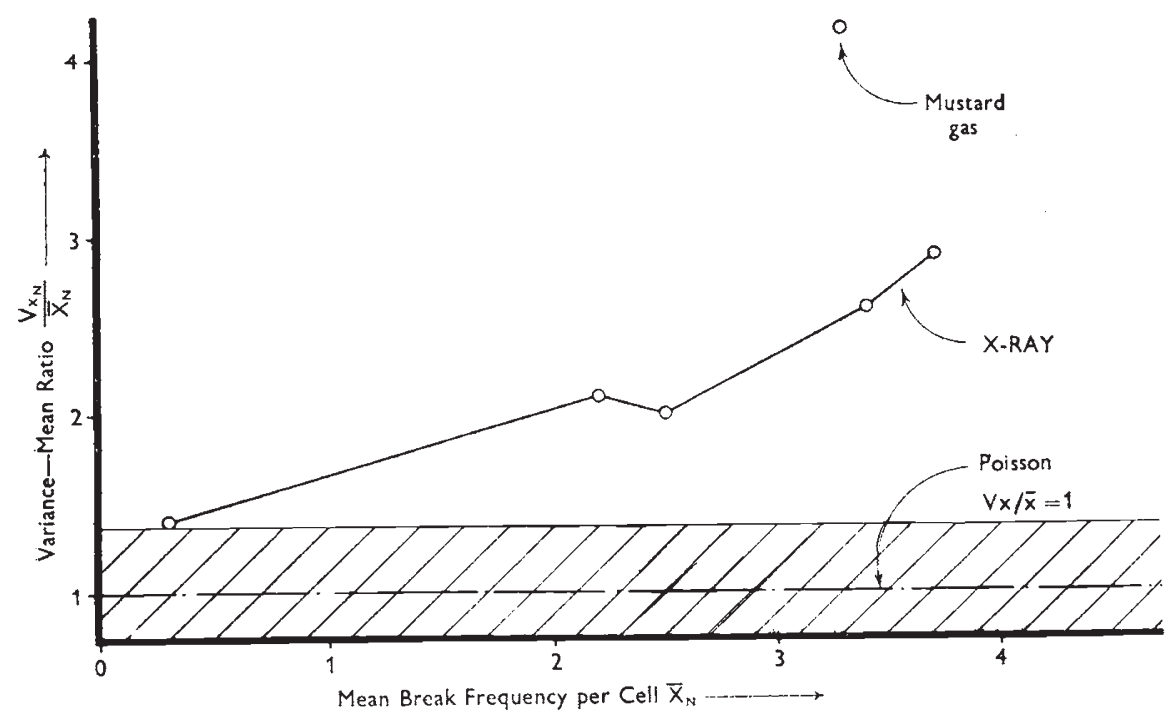

Fic. 4.-Relationship of the variance/mean ratio to the mean number of acentric fragments for X-irradiation and chemical treatment of Tradescantia pollen grains. Data from Darlington and La Cour (1945) and Darlington and Koller (1947).

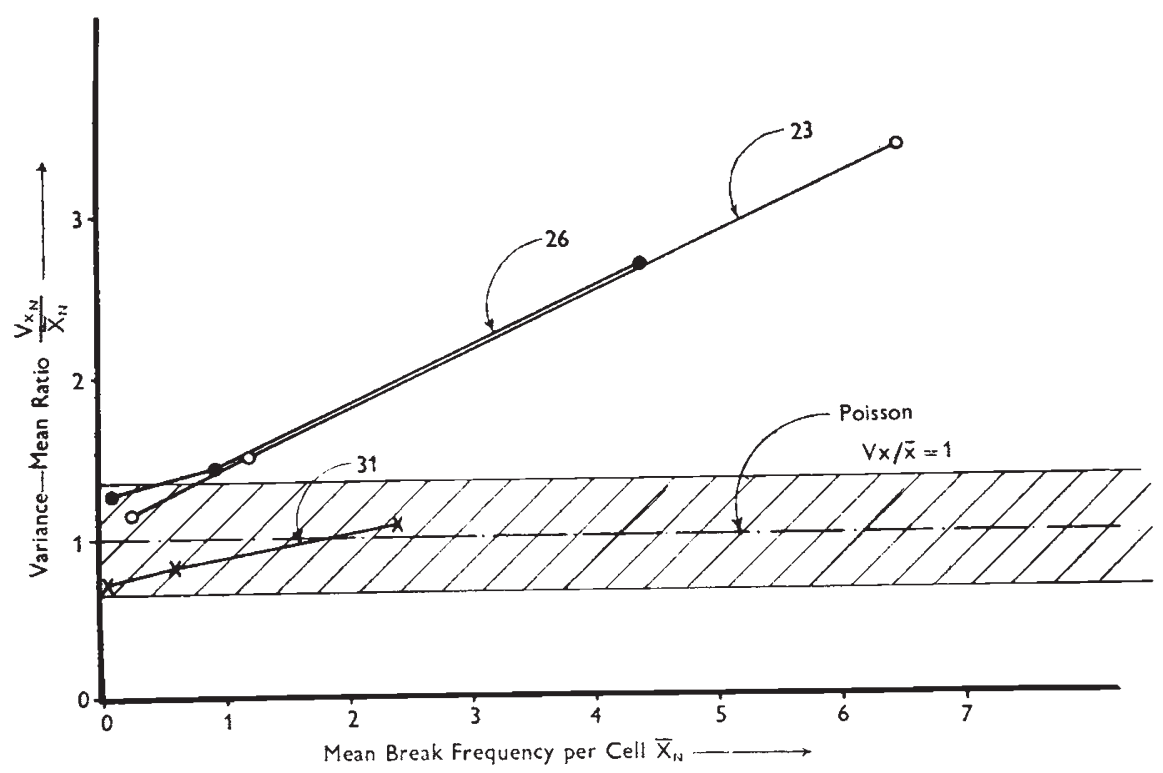

Fig. 5.-Relationship of the variance/mean ratio to the mean number of acentric fragments for X-irradiation of Hyacinthus pollen grains. Data from Newcombe (1942). Irradiation applied 23, 26 and 31 days before fixation. 
those data. It will be seen that the degree of overdispersion is significant at high breakage levels in Hyacinthus and Tradescantia and increases with increase in the mean break frequency. In Hyacinthus it is clear that the degree of dispersion is also dependent on stages in cell sensitivity. The problem requires further examination. However, the analysis certainly supports the results gained in our experiments. An analysis of other published data on X-irradiation shows that most of the distributions are overdispersed. Those cases which do not depart significantly from the Poissonian form are found to have low mean break frequencies.

Few data are available for spontaneous and chemical breakage. Darlington and Upcott's (I94I) data for spontaneous breakage in Tulipa are greatly overdispersed. Data for chemical breakage from Darlington and Koller's (I947) treatment of Tradescantia by sulphur mustard give a variance/mean ratio of $4 \cdot 2(\mathrm{C}=14 \cdot 7)$. For comparison this is represented graphically in fig. 4 with Darlington and La Cour's (1945) irradiation data on the same material.

The Poissonian distribution is thus unsuitable for summarising data on the distribution of breaks between cells. A number of twoparameter distributions describing overdispersion in biological data has been developed (Anscombe, I950; Bliss and Fisher, 1953). Of these the negative binomial is probably best because of its wide applicability and its ease of computation. The negative binomial $(q-p)^{-k}$ has two parameters, the mean $m$ and the exponent $k$; and $p=m / k$ and $q=\mathrm{I}+p$. The expectation of $a_{r}$, where $a_{r}$ is the frequency of the $r$ th class $(r=0, \mathrm{I}, 2, \ldots)$, is

$$
\phi_{r}=\mathrm{E}\left(a_{r}\right)=\mathrm{N} \frac{(k+r-\mathrm{I}) !}{r !(k-\mathrm{I}) !} \cdot \frac{p^{r}}{(\mathrm{I}+p)^{k+r}}
$$

where $\mathrm{N}=$ total number of observations in the sample.

The equation of estimation based on the mean $p k=\bar{x}=\mathrm{S}(f x) / \mathrm{N}$ is fully efficient. The error variance of the mean is $\mathrm{V} \bar{x}=\left(\bar{x}+\frac{\bar{x}^{2}}{k}\right) / \mathrm{N}$.

The estimation of the exponent $k$ offers certain difficulties. Methods and their efficiencies have been discussed by Anscombe (1950) and Bliss and Fisher (1953). The small sample size hardly warrants the estimation of $k$ by the method of maximum likelihood. The simplest method is based on the first and second moments but has an efficiency of only 60 per cent. in this particular case. A more efficient estimate can be obtained for these data using the frequency of the zero class, $a_{0}$. Since $(\mathrm{I}+p)^{k}=\mathrm{N} / a_{0}$, an estimate of $k$ can be found which balances the equation, $\hat{k} \log _{n}(\mathrm{I}+x / \hat{k})=\log _{n}\left(\mathrm{~N} / a_{0}\right)$. Anscombe's graph shows that this estimate has an efficiency of over 98 per cent. for data of the type obtained in these experiments.

Estimates of $m$ and $k$ are shown in table 8. Values of $a_{r}$ with the expectations $\phi_{r}$ calculated from the best-fitting negative binomial for the seven sets of data in each experiment are shown in tables 6 
and 7. A comparison of $a_{r}$ and $\phi_{r}$ indicates that the agreement with the negative binomial exceeds that expected purely on the introduction

TABLE 8

Statistics of the distribution of $\mathcal{N}$, number of fragments per cell. Estimates of parameters and test functions for the negative binomial distribution

\begin{tabular}{|c|c|c|c|c|c|c|c|}
\hline & Tip & $n$ & $\bar{x}$ & $\hat{k}$ & $\mathrm{U}$ & $\mathrm{S}_{\mathrm{U}}$ & $P(U)$ \\
\hline \multirow{7}{*}{ Aged } & I & 206 & 0.03883 & O.OI 590 & $-0.0473^{8}$ & +0.07342 & 0.52 \\
\hline & 2 & 165 & 0.13939 & 0.10490 & +0.03999 & +0.093 I I & 0.57 \\
\hline & 3 & 270 & 0.01851 & 0.00466 & -0.04723 & +0.07416 & 0.53 \\
\hline & 4 & 103 & 0.48543 & $0 \cdot 14925$ & +0.18797 & $+0.6225^{8}$ & 0.76 \\
\hline & 5 & 200 & 0.05000 & 0.05553 & +0.01302 & -0.03950 & 0.74 \\
\hline & 6 & $4 x$ & I 97560 & $0 \cdot 5299 \mathrm{I}$ & $+3.8334^{2}$ & +3.25923 & 0.24 \\
\hline & 7 & $\times 74$ & 0.37931 & 0.19418 & $-0^{\circ}$ I 0890 & $-0 \cdot 70566$ & 0.88 \\
\hline \multirow[t]{7}{*}{$\mathrm{X}$-ray } & I & 207 & 0.16908 & 0.14066 & -0.08545 & +0.06253 & 0.17 \\
\hline & 2 & 252 & 0.10714 & 0.07192 & -0.01931 & +0.05313 & 0.72 \\
\hline & 3 & $3 \times 9$ & $0 \cdot 166$ I 4 & -14.22000 & -0.00005 & $-0.5674^{8}$ & 0.99 \\
\hline & 4 & 216 & 0.15714 & 0.41729 & -0.00912 & +0.03421 & 0.79 \\
\hline & 5 & 193 & 0.14508 & 0.25909 & -0.01833 & +0.03 I 4 & $0.5^{6}$ \\
\hline & 6 & 236 & 0.09746 & 0.1 I 240 & $-0.0255^{6}$ & +0.03782 & 0.50 \\
\hline & 7 & 105 & 0.30476 & 0.6 I I & $+0.045^{6}$ & +0.06395 & 0.48 \\
\hline
\end{tabular}

$\mathrm{U}=\mathrm{S}^{2}-\left[\bar{x}+\bar{x}^{2} / \hat{k}\right] . \quad \mathrm{V}(\mathrm{l})=2 m(\hat{k}+\mathrm{I}) p q^{2}\left(1-\frac{\mathrm{R}^{2}}{-\log _{n}(\mathrm{I}-\mathrm{R})-\mathrm{R}}\right) \mathrm{N}+p^{4} \mathrm{~V} \hat{k}$

where $\mathrm{S}^{2}=$ variance estimate.

$$
\mathrm{V}_{\hat{k}}=\frac{(\mathrm{I}-\mathrm{R})-\hat{k}-\mathrm{I}-\mathrm{R}}{\mathrm{N}\left[-\log _{n}(\mathrm{I}-\mathrm{R})-\mathrm{R}\right]^{2}} \quad \text { and } \mathrm{R}=\bar{x} /(\hat{k}+\bar{x})
$$

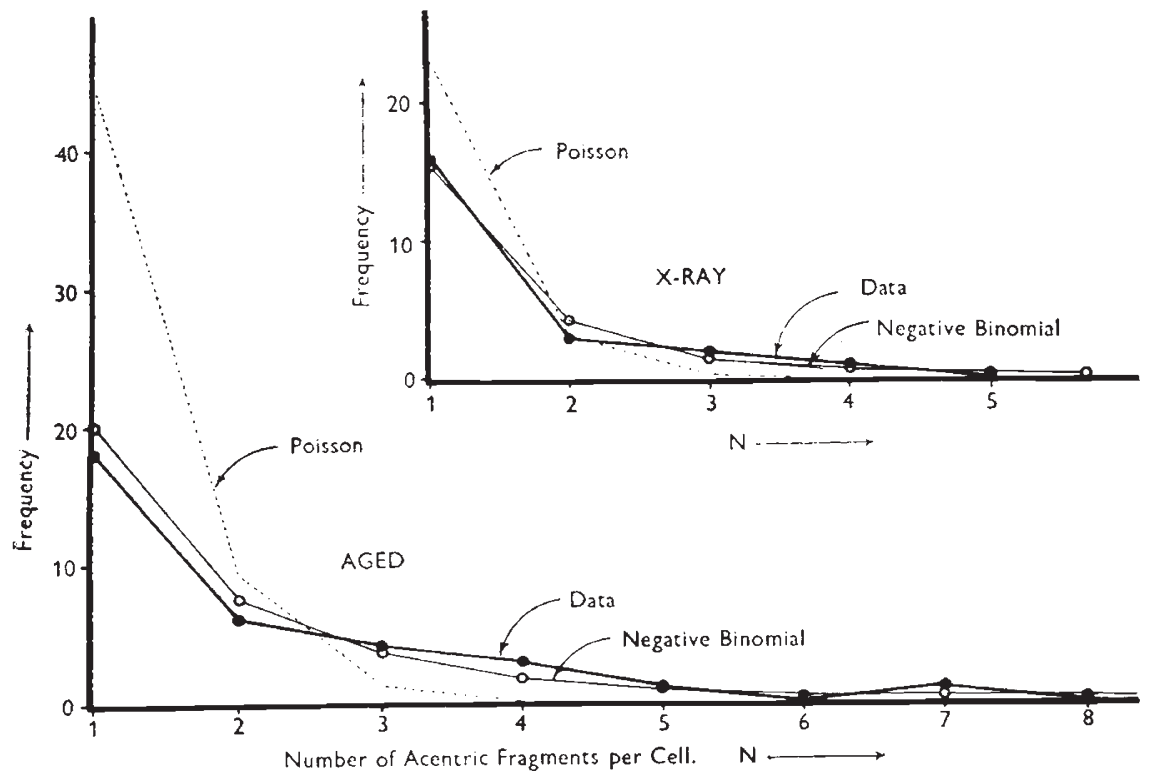

FIg. 6.-Comparison of fits obtained by the negative binomial and Poisson distributions to the data for typical root tips in aged (tip 6) and X-irradiated (tip 7) material.

of another parameter. The distribution for typical sets of data in each experiment are shown graphically in fig. 6. A satisfactory test 
of agreement between $a_{r}$ and $\phi_{r}$ by $\chi^{2}$ is possible only in a few cases because of the low number of classes remaining after pooling to give expectations $\geqslant 5$. A less reliable set of values for $\chi^{2}$ are quoted in tables 6 and 7 where low $\phi_{r}$ values are pooled so that the class expectations are $\geqslant I$. Two efficient tests which avoid grouping of the tail frequencies have been devised by Anscombe. His test criteria, T and $\mathrm{U}$, are based on differences between the observed and calculated moments. Comparison of either test function with its standard error provides a measure of agreement with the negative binomial. The difference, $T$, between the observed third moment and the calculated third moment is efficient when $k$ is estimated efficiently by the moment method. The difference between the observed and calculated second moments, $\mathrm{U}$, is an efficient test function when $k$ is estimated efficiently by the method of zero class frequencies. The latter test is thus suitable for the present data. Values of $\mathrm{U}$ and its standard error are given in table 8. The tests show that the distributions of breaks in the cells are adequately described using the negative binomial distribution.

A negative binomial distribution can arise as the result of several quite different models which are discussed by Anscombe, and by Bliss and Fisher. They include: (a) inverse binomial sampling; (b) heterogeneous Poisson sampling; (c) randomly distributed colonies ; $(d)$ immigration-birth-death process.

In the case of breakage produced by irradiation suitable arguments can be constructed from models $(b)$ and $(c)$ above. For spontaneous breakage, an argument based on model $(d)$ is an additional possibility, but it is doubtfully distinct from $(c)$. Discrimination between these and other models leading to the negative binomial can be based only on the general biological feasibility of the proposed mechanism.

Let us consider the two possible models. A negative binomial with exponent $k$ is realised if the members of a population constitute a mixed or "compound" Poisson distribution such that the means of the individual Poisson distributions have a Type III distribution, proportional to a $\chi^{2}$ distribution with $2 k$ degrees of freedom.

The conditions of this model are simply met if we consider the specific breakage sensitivity (intensity), $\xi$, of individual cells at a fixed dose, to be a positive continuous variant. The simplest frequency distribution which $\xi$ might be expected to follow would be the Eulerian or Pearson Type III distribution. If breakage is due to the direct action of an ion cluster the probability of obtaining $\mathrm{N}$ breaks in a cell with intensity $\xi_{i}$ is $e^{-\xi^{i}} \xi_{i}^{\mathrm{N}} / \mathrm{N}$ !. The distribution of $\mathrm{N}$ in a sample of cells where $\xi_{i}$ has a Type III distribution will be a negative binomial.

While there is evidence of some variation of the sensitivity $\xi$ in cells at different stages of development, the range of sensitivity even in a population of growing cells seems too small to result in significant overdispersion. In the population of dormant cells used in these experiments, we can assume only a very small range in sensitivity. In addition the hypothesis does not provide any explanation for the 
similarity between the distribution of spontaneous and radiationinduced breaks.

As regards the second possible model a negative binomial distribution results from sampling a population whose members are grouped in colonies which are randomly distributed in some continuous dimension like space or time, and where the numbers of individuals in the colonies are distributed independently in a logarithmic distribution. This model is a simple "contagion" type model and seems to be of more general importance than models based on Neyman's or Thomas's distributions.

In a crude sense we may say that in our material " contagion" exists within cells (and possibly between cells), such that cells which suffer damage are more prone to further damage, i.e. a local disturbance of sufficient magnitude to cause breakage, results also in a regional instability which lowers the threshold value for further breakage in the general surroundings. An obvious source of such contagion is some diffusable chemical agent produced within the tissue. This is a concept for which there is an increasing amount of evidence in modern radiobiology.

A mechanism based on cumulative chemical action would explain the similarities which exist in the pattern of breakage produced by chemicals, by radiations and spontaneously. Similar patterns both within chromosomes and between cells could be realised if the ion clusters produced by irradiation are the centres of production of some active radicals or mutagenic substances.

A model representing this cumulative chemical effect must account for the contribution of various numbers of production centres and for the diffusion of the mutagen in time and space. As a first approximation we may utilise the number of observed breaks as a function of the number of primary centres. We may then construct a transition function for the probabilities of successive events of the form.

$$
\frac{\mathrm{P}\{\mathrm{N}+\mathrm{I}\}}{\mathrm{P}\{\mathrm{N}\}}=\frac{a+\mathrm{N}}{\beta+t}
$$

where $\alpha$ and $\beta$ are constants $>0, N$ is the number of breaks and $t$ is the aggregate diffusion path. This yields a probability function of obtaining $\mathrm{N}$ events as

$$
p\{\mathrm{~N}\}=\left(\frac{a}{a+\xi t}\right)^{a} \cdot \frac{a(a+\mathrm{I}) \ldots(\alpha+\mathrm{N}-\mathrm{I})}{\mathrm{N} !} \cdot\left(\frac{\xi t}{\alpha+\xi t}\right)^{N}
$$

with $\xi=\alpha / \beta$. This is a negative binomial with mean $=\xi t$ and variance $=\xi t+(\xi t)^{2} / a$. So that $m=a t / \beta, k=a, p=t / \beta$ and $q=\mathrm{I}+t / \beta$ and the distribution function is identical with that obtained from the model based on heterogeneous Poisson sampling.

It is perhaps worth mentioning briefly at this stage a closely related model which may apply. If the initial events are distributed at random but the derived substances obey a geometrical distribution 
as opposed to the logarithmic form in the above model, the resulting distribution will be a Polya distribution (Anscombe, I950). In the absence of very extensive data, discrimination between the negative binomial and the Polya would be extremely difficult. In any case such minor variations are unimportant at this juncture when the main consideration lies in the choice between a direct or an indirect action.

\section{CUMULATIVE ACTION}

The concept of cumulative action is based on the existence of intermediate chemical steps between the primary physical events of $\mathrm{X}$-irradiation and final breakage. It thus removes the gross simplifications of the target theory and explains immediately the many similarities in effects and distributions of damage obtained after treatment of chromosomes by such different agents as ageing, irradiation and chemical mutagens.

The target theory can be considered to be the limiting case which is approached when interaction between ion clusters is reduced by isolating them in time or space. Under conditions of isolation the probability of reaching critical concentrations of active mutagen will be limited to the immediate proximity of the primary ion clusters and particular breaks will be ascribable to particular particles as demanded by the target theory. This appears to be the case at low doses or at very low intensities. However, there is increasing evidence, some of which has been given above, that at high doses serious deviations from the expectations of the target theory occur.

These problems have been investigated in three ways: (I) by altering the total dose keeping intensity constant, (2) by altering the intensity at which a constant dose is given and (3) by fractionating a constant dose. The target theory would predict that the efficiency of breakage per unit dose should remain constant under all these conditions. Any cumulative effect would show by departures from linearity under (I) and by an increased number of breaks per unit dose at higher intensities or without fractionation under (2) and (3). Where deviations from the expectations of the target theory occur they are always of the type predicted by the hypothesis of cumulative action. There is, however, great controversy in the interpretation of these deviations, various authors accounting for them in terms of non-random re-union, changes in rates of re-union under different physiological conditions, etc. It would seem that greater consideration should be given to explaining all the results in terms of cumulative action.

In particular more experimental work is needed on the distribution of breaks between cells at high intensities and doses. Cumulative action leading to a negative binomial distribution predicts that the variance should exceed the mean by a quantity approximately equal 
to $\frac{\bar{x}^{2}}{k}$ We have seen that in some data analysed here (figs. $4^{-6}$ ) this expectation is realised. In other investigations, e.g. Sparrow (I95I), complex changes in nuclear sensitivity apparently cause both mean and the "contagion factor", $k$, to undergo changes.

There are two further aspects of irradiation work which require discussion in terms of cumulative action. They are the effect of oxygen and of ion density. The interaction of oxygen with X-irradiation indicates that irradiation initiates some chemical chain-reaction involving oxygen. The type of compounds concerned with breakage has not yet been determined but they are probably peroxy and epoxy compounds (Read, 195I ; Phillips, 1956). These chain-reactions, which can be interrupted in various ways, provide the right chemical models for cumulative action. As regards ion density, it has been demonstrated that the yield of peroxide increases with oxygen for low ion density radiation but for high ion density radiation, e.g. $a$-rays, oxygen has no such effect, the products being localised to the track of the particle. It is hoped to investigate experimentally the effects of some of these variables on overdispersion.

\section{SUMMARY}

1. A comparison of chromosome breakage in Allium cepa induced by ageing ( 4 year storage) and by $\mathrm{X}$-irradiation $(2.4 \mathrm{Kr}$ ) of the dry seed shows great similarity in pattern.

2. The types of aberration produced are the same in the two treatments. Excluding minutes, $9^{8}$ per cent. of all aberrations are simple terminal deletions. Chromatid breakage appears to be absent and non-sister re-union rare.

3. The distribution of breaks within the chromosomes was studied by cletermining the frequency distribution of length of acentric fragments. Near-terminal regions of the chromosome arm are very susceptible to damage; centromere regions are susceptible but less so ; mid-arm regions are resistant. The distributions of breaks within chromosomes are very similar in the two treatments.

4. The absence of correlation between the length of acentric fragments and the number induced in the cell indicates a random or near-random distribution of damage between chromosome arms after both treatments.

5. The distribution of breaks between cells of the one seed shows overdispersion as compared with the Poisson distribution. Overdispersion is greater after ageing than after $\mathrm{X}$-irradiation for the same mean number of breaks. The overdispersed distributions obtained after both treatments can be fitted with a high degree of efficiency by the negative binomial.

6. Analysis of previously published data shows that overdispersion is frequent in breaks induced by $\mathrm{X}$-irradiation, by chenical mutagens 
and spontaneously. In general, overdispersion increases as the mean number of breaks increases.

7. It is suggested that these similarities in pattern of breakage induced by very different agents indicate a similar chemical basis for the induction of breakage. In particular, the evidence indicates that the initial sites of ionisation after X-irradiation interact, presumably by the production of mutagenic substances or radicals which have a definite half-life within the cell, during which time they can diffuse in both time and space. A "contagion" model based on cumulative action is proposed to explain the negative binomial distribution.

\section{REFERENCES}

ANscombe, F. J. I950. Sampling theory of the negative binomial and logarithmic series distributions. Biometrika, 37, 358-382.

BLISS, C. I., AND FISHER, R. A. 1953. Fitting the negative binomial distribution to biological data. Biometrics, 9, I 73-200.

CAMARA, A. I941. O preoblema da fragmentacao cromosomica operada pelos raios X, estudado no Triticum monococcum. Agronomia Lusitana, 3, 341-359.

CATCHESIDE, D. G., LEA, D. E., AND THODAY, J. M. I946. The production of chromosome structural changes in Tradescantia microspores in relation to dosage intensity and temperature. F. Genet., 47, 137-149.

DARLINGTON, C. D., AND Koller, P. C. I 947 . The chemical breakage of chromosomes. Heredity, I, I87-22 I.

Darlington, C. D., AND la Covir, L. F. 1945. Chromosome breakage and the nucleic acid cycle. F. Genet., 46, 180-267.

DARLINGTON, C. D., AND UPCOTT, M. B. I94I. Spontancous chromosome change. J. Genet., 4I, 297-338.

DEUfEL, J. I $95 \mathrm{I}$. Untersuchungen über den Einfluss von Chemikalien und Röntgenstrahlen auf die Mitose von Vicia faba. Chromosoma, 4, 239-272.

FAHMY, O. G., AND BIRD, M. J. I953. Chromosome breaks among recessive lethals induced by chemical mutagens in Drosophila melanogaster. Symp. on chromosome breakage. Heredity, 6, Suppl., I 49-1 59 .

FORD, C. E. 1949. Chromosome breakage in nitrogen mustard treated Vicia faba root tip cells. P. Int. Gen. C. (8) (Hereditas, Suppl. Vol.), 570-57 I.

GRAY, L. H. $195 \mathrm{I}$. Biological actions of ionising radiations. Progress in Biophysics and Biophysical Chemistry, 2, 240-305.

HAQUE, A. 1953. The fractionation effect in Tradescantia. Symp. on chromosome breakage. Heredity, 6, Suppl., 35-40.

KOLleR, P. C., AND AHMED, I. A. R. S. 1942. X-ray induced structural changes in the chromosomes of Drosophila pseudo-obscura. 7. Genet., 44, 53-72.

LANE, G. R. 1951. X-ray fractionation and chromosome breakage. Heredity, 5, I -35 .

LANE, G. R. 1953. Interpretation in X-ray chromosome breakage experiments. Symp. on chromosome breakage. Heredity, 6, Suppl., 23-34.

LEA, D. E. 1946. Actions of Radiations on Living Cells. London: Cambridge University Press.

LOVELEss, A. 1953. Chemical and biochemical problems arising from the study of chromosome breakage by alkylating agents and heterocyclic compounds. Symp. on chromosome breakage. Heredity, 6, Suppl., 293-298.

LOVELESS, A., AND REVELl, S. H. 1949. New evidence on the mode of action of " mitotic poisons". Nature, ${ }_{16} 64,938-955$.

MCLEISH, J. I953. The action of maleic hydrazide in Vicia. Symp. on chromosome breakage. Heredity, 6, Suppl., I 25-147. 
NसwCOMBe, H. B. 1942. The action of X-rays on the cell. I. The chromosome variable. J. Genet., 43, 145-1 7 1.

rhilitips, L. L. 1956. Effect of free radicals on chromosomes of barley. Science, $124,889-890$.

READ, J. I951. Physical aspects of the biological action of ionising radiations. British 7. of Afp. Physics, 2, 337-344.

REVELL, S. H. I 953 . Chromosome breakage by $\mathrm{X}$-rays and radiomimetic substances in Vicia. Symp. on chromosome breakage. Heredity, 6, Suppl., ro7-1 24.

SAX, K., AND MATHER, K. 1939. An analysis of progressive chromosome splitting. J. Genet.. 37, 483-490.

SPARROW, A. H. I95I. Radiation sensitivity of cells during mitotic and meiotic cycles with emphasis on possible cytochemical changes. Ann. N.Y. Acad. Sci., 5I, I 508-I540.

SPARROW, A. H.. AND SPARROW, R. C. I 949 . The frequency of spontaneous chromosome breakage in Trillium. Genetics, 35, 135.

sukнатмe, p. v. 1938. On the distribution of $\chi^{2}$ in samples of the Poisson series. Suppl. 7. Roy. Stat. Soc., 5, 75-79.

swanson, C. P. 1942. The effect of U.V. and X-ray treatment on the pollen tube chromosomes of Tradescantia. Genetics, 27, 49 I-503. 